octodynets. So, too, Joule's equivalent $J$, which is about $" 4 \cdot 2 \times 10^{7}$ ergs per gramme-degree Centigrade" (Everett's "Units and Physical Constants."), would be more easily remembered as $4 \cdot 2$ heptergons. Again, the velocity of light would be (approximately) expressed as 3 octometrons per second, or 3 decavelons, if the word vel were adopted for the unit speed in the C.G.S. system-namely, that of I centimetre (or dimetret) per second. I have chosen these instances, as cases where the prefixes mega- and micro- would be of little use as aids to expression or memory.

The system I am advocating coincides exactly with the method, which I believe most intelligent teachers of arithmetic are adopting, of reckoning the place of any digit of a number by its distance, not from the decimal point, but from the unit's digit. This distance it has been proposed to call the order of the digit, so that the order of the unit's digit is o; those of the tens, hundreds, \&c., 1, 2, \&c.; and those of tenths, hundredths, \&c., $-\mathbf{I},-2$, \&c. Then, if the order of a number be regarded as that of its highest digit, its order is the characteristic of its logarithm. I forbear to dilate on the advantages of this reform in arithmetical language, but it is obvious that the proposed system naturally arises out of it. If the British Association or the Physical Society should, after discussion, accept the principle of the proposed nomenclature, and give it the stamp of their authority, I believe they would add to the benefits they have already conferred on science by the introduction of the C.G.S. system of units. My proposal would not extend to attempting to replace the words in ordinary use-kilometre, millimetre, kilogramme, \&c. - unless they, in the course of time, lied out, replacer by the synonyms here proposed on the principle of the "survival of the fittest."

Harrow, February 27.

Robt. B. Hayward.

IN NATURE of February 23 (p. 388) there appears an interesting letter from Prof. A. W. Riicker with reference to the equivalent value of the "micromillimetre." It is therein mentioned that the micromillimetre is conmonly employed by biologists as equivalent to one-thousandth of a millimetre; but that the proper name for the thousandth of a millimetre $(\mu)$ is "micromētre," and not " micromillimetre."

Permit me, however, to suggest that even the denomination "micrometre," may be hardly acceptable to scientific workers. The denomination for the measure of the one-thousandth of a millimetre $(\mu)$, or $0^{\circ} 000001$ metre, is "micron," and not " micrometre."

For the "micron" we have the authority of the "Comite International des Poids et Mesures." One shudders at the thought of the confusion likely to arise when computers are required to deal with both micromētre-units and micrometerdivisions.

The Comité International have a'so recommended the use of the following metric denominations for minute measurements :-

\begin{tabular}{|c|c|c|c|c|}
\hline 1)enomination. & & Symbs & & Equivalent. \\
\hline Micron $\ldots . .$. & ; & $\mu$ & & 0.001 millimetre. \\
\hline Microgramme & ... & $\gamma$ & $\ldots$ & o.oor milligrame. \\
\hline Millilitre $\quad \ldots$ & $\ldots$ & $m l$ & $\ldots$ & o.0or litre. \\
\hline Microlitre & $\ldots$ & $\lambda$ & $\ldots$ & 0.00000 I litre. \\
\hline
\end{tabular}

For the millionth of a millimetre we have at present the (C.G.S.) denomination "micromillimetre" $(\mu \mu)$, as pointed out by Prof. Rücker.

7 Old Palace Yard, Westminster, February 27.

AlLow me to add a few remarks to Prof. A. W. Ruicker's letter, published in your issue of February 23 (p. 388).

Mr. O. J. Broch, Correspondent of our Institute in its Section of Mechanics, and Director of the International Board of Weights and Measures, having kindly undertaken to ascertain by actual measurement my pendulum's coefficient of expansion by heat, began by asking how old it was. On my expressing surprise at such a question, he told me that, having carefully measured the length of a brass rod recently made and I metre long, he found that it became shorter by 8 microns in the first year, and 3 more in the second one. Micron is currently used here to express $\mathbf{I}$ / Icco of a millimetre. French botanists call it $\mu$, and seldom use its first decimal because they cannot see such.a small space.

The only objection against micron is that, unlike other subdivisions of the metre, it does not define its length by its name.
But the word metre has itself the same fault. It is the tenmillionth part of a quarter meridian, and is, according to Clarke's computations, too short by $0^{\prime} 2$ millimetre, or, more exactly, 187.7 microns. Improvements in geodesy will probably alter in either sense that fraction which is too small to disturb terrestrial requirements.

The quarter meridian being the true basis of our metrical system, it ought to have a name of its own, and might be called megist, as being the greatest space accurately measured. It should be the metre used in astronomy. Thus the velocity of light would be 30 megists, the motion of the star Aldebaran in the line of sight would be 18 megists per hour, and the sun's distance 15,000 megists \pm 50 . To give the latter in kilometres or miles is tantamount to describing the height of St. Paul's in London as being $1,100,000,000$ microns. It is useless to express a distance in units so small that one of them may be added or subtracted without altering our useful notion of the whole sum. Moreover, those who can grasp at once a practical idea of such huge numbers are few and far between.

February 29. ANTOINE D'ABBADIE.

\section{Coral Formations.}

Mr. G. C. Bourne's observations, as far as described in last week's NATURE (p. 4I4), appear to corroborate fully the view that corals grow more rapidly and luxuriantly on those parts of a reef or bank where there is an abundant supply of food, and only in scattered patches where the food supply is limited or where there is a quantity of sand or other inorganic materials in the currents. Hle states his belief that "the favourable conditions are due to the action of currents on coral growth." If it be not the food in these great oceanic currents, then Mr. Bourne should tell us what it is in "the action of currents" bathing the outer slopes of a reef that renders them favourable to growth does he hold to the old view of more oxygen in the water?

It is to be hoped that $\mathrm{Mr}$. Bourne has observed some of the corals feeding on the outer slope or in the lagoon, and can tell us of what their food consists. It will be interesting to know if he has worked his tow-nets in the outer currents, in the "strong currents," and in the still water, and has made a comparison of the results. If he has done so, his paper will doubtless be one of great interest and value.

There would appear to be a slip of the pen in the passage where $\mathrm{Mr}$. Bourne refers to a current impinging directly on a slope.

JOHN MURRAY.

\section{An Incorrect Footnote and its Consequences.}

ThANiss to the wide circulation of NATURE, my original note with the above heading has attracted attention in quite a number of the proper quarters. Several letters have reached me on the subject, and more than one of the writers, after reporting that the Demonstratio eliminationis Crameriane had been found properly catalogued under De Prasse, proceed in consequence to express their surprise at Baltzer's mistake. Mr. Copeland's letter in yesterday's NATURE (p. 343) adds another instance of this correctness of cataloguing. The additional fact, which he mentions, that there are two copies of the original edition of the Demonstratio in the Dun Echt library is very interesting, and is a fresh proof of the existence there of valuable rarities.

When, however, Mr. Copeland diverges into the fruitless path of "the might have been" he is much less pleasantly instructive. Having read my letter on the search for a work by Mollweide, and on the discovery that the work meant was not by Mollweide at all but by De Prasse, Mr. Copeland turns to his catalogue under Mollweide, finds a cross-reference to De Prasse, looks up De Prasse, piclss out the desired plum, and is pleased accordingly. In all this there is nothing singularly lucky or otherwise: it is exactly what ought to have happened. Mr. Copeland apparently thinks that the cross-reference in the Dun Echt catalogue was the missing link; but if he had had occasion to look up other catalogues besides his own he would have found the same cross-reference or a more complete one, and might then have given my helpers in the search a little more credit. The fact is that the booklet of mathematical tables which was the cause of the cross-reference (and whose title Mr. Copeland carefully (ranscribes) is a comparatively common book, having gone in its time through several editions. Its name is thus of not infrequent occurrence in catalogues, being placed under De Prasse with a reference to Mollweide, or vice versî́; and, so catalogued, 